\title{
Expression of aspartyl beta-hydroxylase and its clinicopathological significance in hepatocellular carcinoma
}

\author{
Zhi-Hong Xian, Shu-Hui Zhang, Wen-Ming Cong, He-Xin Yan, Kui Wang and \\ Meng-Chao Wu \\ Department of Pathology, Eastern Hepatobiliary Surgery Hospital, Second Military Medical University, \\ Shanghai, China
}

\begin{abstract}
The human aspartyl beta-hydroxylase is a highly conserved enzyme that hydroxylates epidermal growth factorlike domains in transformation-associated proteins. The aspartyl beta-hydroxylase gene is upregulated in many human malignancies. The purpose of this study was to investigate the expression of aspartyl beta-hydroxylase in hepatocellular carcinoma. Aspartyl beta-hydroxylase mRNA levels were measured in 161 hepatocellular carcinomas and paired nontumoros liver tissues by conventional and real-time RT-PCR. Immunohistochemical staining of aspartyl beta-hydroxylase was performed using EnVision Plus system. The results showed that aspartyl beta-hydroxylase was overexpressed in 150 of 161 hepatocellular carcinomas (93\%), including 45 of 48 unifocal small hepatocellular carcinomas (94\%). Aspartyl beta-hydroxylase was highly expressed in hepatocellular carcinoma cells in contrast to its low level of expression in non-neoplastic liver cells. The protein expression level of aspartyl beta-hydroxylase in the hepatocellular carcinoma was parallel with the mRNA expression level $(r=0.6594, P<0.0001)$. A significantly higher tumor aspartyl beta-hydroxylase overexpression level was associated with the presence of intrahepatic metastasis and the progression of histological grades. In conclusion, aspartyl beta-hydroxylase is overexpressed frequently in hepatocellular carcinoma, including early-stage small hepatocellular carcinoma, indicating that overexpression of aspartyl beta-hydroxylase plays a role in the development and progression of hepatocellular carcinoma.
\end{abstract}

Modern Pathology (2006) 19, 280-286. doi:10.1038/modpathol.3800530; published online 9 December 2005

Keywords: hepatocellular carcinoma; aspartyl beta-hydroxylase; real-time RT-PCR; immunohistochemistry; marker

Hepatocellular carcinoma is one of the most frequent human cancers worldwide and has become the second cancer killer in China since the 1990s. ${ }^{1,2}$ Epidemiological studies in high-risk populations have identified chronic hepatitis B or C virus infections as well as dietary exposure to aflatoxin B1 as major factors in the etiology of this disease. ${ }^{3}$ The genesis of human cancers is a multistep process reflecting cumulative genetic alterations that include activation of oncogenes or inactivation of tumor suppressor genes. ${ }^{4,5}$ Although many tumors are detectable by ultrasonography, helical computed tomography, or magnetic resonance imaging, these approaches seldom reveal hepatocellular carcinoma that are smaller than $1 \mathrm{~cm}$ in diameter. ${ }^{6,7}$ Therefore,

Correspondence: Dr S-H Zhang, MD, Department of Pathology, Eastern Hepatobiliary Surgery Hospital, Second Military Medical University, 225 Changhai Road, Shanghai 200438, China.

E-mail: zhangshuhui100@sohu.com

Received 6 September 2005; revised and accepted 18 October 2005; published online 9 December 2005 these methods have limited value for detecting hepatocellular carcinoma at an early stage. Recently, some molecular factors such as tumor proliferative indices, nuclear DNA ploidy, and expression of genes, growth factors, and hormone receptors have been used to predict clinical outcome in patients with hepatocellular carcinoma. ${ }^{8,9}$ Specific and sensitive biomarkers for hepatocellular carcinoma would be used to detect preclinical disease, and to target therapy if the associated antigens are expressed on the cell surface.

The human aspartyl beta-hydroxylase is a highly conserved enzyme that hydroxylates epidermal growth factor-like domains in transformation-associated proteins. Since aspartyl beta-hydroxylase is expressed at very low or undetectable levels with reactive, regenerative, or inflammatory disease processes-associated bile duct proliferation, ${ }^{10}$ it is unlikely that aspartyl beta-hydroxylase simply promotes cell growth or DNA synthesis. On the other hand, the finding that experimental overexpression of aspartyl beta-hydroxylase causes transformation 
of NIH3T3 cells ${ }^{10}$ suggests that aspartyl beta-hydroxylase has a functional role in malignancy. It has been demonstrated previously that the aspartyl betahydroxylase gene is upregulated in human malignancies such as breast, colon, liver, and bile duct tumors. ${ }^{10-12}$ But the role of aspartyl beta-hydroxylase in cell migration, oncogenesis, cell differentiation, invasiveness, properties, and cellular functions that propagate the malignant phenotype are not understood. In this study, aspartyl beta-hydroxylase expression was examined in hepatocellular carcinoma. We also determined whether the clinicopathological features characterize correlates of aspartyl beta-hydroxylase overexpression in hepatocellular carcinoma to determine if aspartyl betahydroxylase levels can be used to help predict the clinical course of disease.

\section{Materials and methods}

\section{Patients and Samples}

In all, 161 hepatocellular carcinoma specimens from surgically resected tissues were obtained from Eastern Hepatobiliary Surgery Hospital, Second Military Medical University. All patients did not receive any prior therapy. This study included 116 men and 45 women. The ages ranged from 29 to 78 years (medium is 51 years). A total of 106 patients had serum alpha-fetoprotein (AFP) $\geq 20 \mu \mathrm{g} / \mathrm{l}$. There were 122 cases positive for hepatitis B surface antigens (HBsAg). The median tumor size was $7.1 \mathrm{~cm}(1.0$ $15.8 \mathrm{~cm})$. In all, 48 cases had unifocal small hepatocellular carcinomas $(\leq 2 \mathrm{~cm})$ and 113 had advanced hepatocellular carcinomas $(>2 \mathrm{~cm}$ ). Histopathological diagnosis was made according to the World Health Organisation histological classification of tumors of the liver and intrahepatic bile ducts (2000)..$^{13}$ A total of 53 hepatocellular carcinomas were well differentiated, 80 were moderately differentiated, and 28 were poorly differentiated. Of the 148 patients, 113 were absent or not intact capsules, and 107 had evidence of intrahepatic metastasis (portal vein invasion and/or intrahepatic dissemination). In total, 95 hepatocellular carcinomas were detected accompanying liver cirrhosis and the remaining cases were 47 chronic hepatitis and 19 basic normal liver tissue.

Fresh tumor tissues and adjacent nontumorous liver tissues of hepatocellular carcinoma patients were obtained immediately after resection of the tumors. One part of the tissues was snap frozen in liquid nitrogen immediately and stored at $-70^{\circ} \mathrm{C}$. The other part was fixed in 10\% buffered formalin and embedded in paraffin.

\section{Extraction of mRNA and Preparation of cDNA}

Total RNA from hepatocellular carcinoma tissues was extracted from tissue using $10-\mu \mathrm{m}$ frozen sections. For the isolation of RNA from defined areas with at least $80 \%$ tumor cells, all tumors were manually microdissected under direct visual control through a dissecting microscope. Total RNA in frozen tissues was extracted using TRIZOL (Invitrogen) following the manufacturer's recommendations. Total RNA was digested with DNase I (Invitrogen) and was used for first-strand cDNA reaction. The reaction mixture was comprised $0.5 \mu \mathrm{g}$ of DNase I-treated RNA, $1 \times$ reverse transcriptase buffer, $4 \mathrm{mM}$ dNTP mix, $1 \times$ random primer, and $2.5 \mathrm{U} / \mu \mathrm{l}$ multiScribe reverse transcriptase (PE Applied Biosystems). ${ }^{14}$ Each sample was treated with the same protocol, with the exception of the addition of reverse transcriptase, to exclude the presence of interference due to genomic DNA.

\section{RT-PCR}

RT-PCR was performed in a $25-\mu$ l reaction mixture containing $2 \mu \mathrm{l}$ of cDNA template, $500 \mathrm{nM}$ of each primer, and $1 \mathrm{U}$ of Taq DNA Polymerase (AmpliTaq Gold; Roche Molecular Systems, Pleasanton, CA, USA), as follows: after one cycle at $95^{\circ} \mathrm{C}$ for $12 \mathrm{~min}$, 30 cycles at $94^{\circ} \mathrm{C}$ for $1 \mathrm{~min}, 61^{\circ} \mathrm{C}$ for $1 \mathrm{~min}$, and $72^{\circ} \mathrm{C}$ for $1.5 \mathrm{~min}$, followed by $72^{\circ} \mathrm{C}$ for $10 \mathrm{~min}$. The nucleotide sequences for the primer pairs were as follows: aspartyl beta-hydroxylase: sense 5'-ATC TGT CTG GCA ACG CTC A-3' (nt 1748-1766, GenBank Accession no. NM_004318), antisense 5'ACA TCG AAT CTT GCA GCC T-3' (nt 2189-2172), spanning two extrons and three introns, $442 \mathrm{bp}$. As an internal quantitative control of the gene expression, the glyceraldehyde-3-phosphate dehydrogenase (GAPDH): sense 5'-GTT GGA GGT CGG AGT CAA CGG A-3', GAPDH, antisense 5'-GAG GGA TCT CGC TCC TGG AGG A-3' (240 bp) is used. ${ }^{15}$ The PCR products were separated by electrophoresis on $2 \%$ agarose gels.

\section{Real-Time RT-PCR}

Relative quantitation by real-time RT-PCR was performed using SYBR-green detection of PCR products in real time with the Light Cycler (Roche Diagnostics, Meylan, France), which exploited the ability of SYBR green to fluoresce after hybridization with a double-strand DNA. ${ }^{16-18}$ The analyses were carried out in $20 \mu \mathrm{l}$ glass capillaries using the Light Cycler fast start DNA master SYBR green kit (Roche Diagnostics). Then, $1 \mathrm{mmol} / \mathrm{l}$ of each primer and $3 \mathrm{mmol} / \mathrm{l}$ of $\mathrm{MgCl}_{2}$ in the total volume of $20 \mu \mathrm{l}$ were used in each real-time RT-PCR amplification. The real-time RT-PCR cycle started with the initial denaturation at $95^{\circ} \mathrm{C}$ for $10 \mathrm{~min}$, followed by 45 cycles of denaturation at $95^{\circ} \mathrm{C}$ for $10 \mathrm{~s}$, annealing at $61^{\circ} \mathrm{C}$ for $10 \mathrm{~s}$, and elongation at $72^{\circ} \mathrm{C}$ for $10 \mathrm{~s}$. As an internal quantitative control of the gene expression, GAPDH gene expression was determined as reported previously. ${ }^{19-21}$ The aspartyl beta-hydroxylase and 
GAPDH gene expressions of all cDNA samples were determined by fluorescence from SYBR green using the Light Cycler software Version 3.5 (Roche Diagnostics), and the ratios of aspartyl beta-hydroxylase and GAPDH gene expressions represented the normalized relative levels of aspartyl betahydroxylase expressions. ${ }^{19,22}$ A no-template negative control was also included in each experiment. Analyses of all tumor samples were carried out in at least two replicates, and the mean value was calculated. Only samples with values corresponding to s.d. $<20 \%$ were included in the study.

\section{Immunohistochemistry}

To evaluate and localize aspartyl beta-hydroxylase expression in hepatocellular carcinoma tissues, immunohistology was carried out on carcinoma tissues and their corresponding nontumorous liver tissues. Sections ( $4 \mu \mathrm{m}$ thick) were prepared from formalin-fixed and paraffin-embedded tissues, dried for $2 \mathrm{~h}$ at $60^{\circ} \mathrm{C}$, and dewaxed in xylene and graded ethanols. Nonspecific protein staining was blocked by preincubation for 5 min with 1:10 diluted Normal Horse Serum (Vector Laboratories). Aspartyl betahydroxylase monoclonal antibody (Maxin Biotech Inc, China) was cloned from a generated library of monoclonal antibody to FOCUS hepatocellular carcinoma cells. ${ }^{10}$ Immunohistochemical staining of aspartyl beta-hydroxylase was performed with the Dako Envision Plus System (Dako, Carpinteria, CA, USA) following the manufacturer's instruction with modifications. We regarded cells as immunoreactive for aspartyl beta-hydroxylase when the signal was clearly observed in the cell surface membranes and/ or cytoplasm.

Only membrane staining was considered positive, whereas cytoplasmic staining was ignored. In each case, the intensity (weak, moderate, or strong) and pattern (incomplete or complete) of membrane staining and percentage of neoplastic immunoreactive cells were evaluated. To compare the correlation between the RNA and protein expression, quantification of aspartyl beta-hydroxylase positive cases was performed by classifying them into five groups; 0 , no appreciable complete membrane staining and strong complete membrane staining in less than $5 \%$ of cells; $1+$, strong complete membrane staining in fewer than $10 \%$ of cells and moderate complete membrane staining in $6-25 \%$ of cells; $2+$, strong complete membrane staining in fewer than $10 \%$ of cells and moderate complete membrane staining in $26-50 \%$ of cells; $3+$, strong complete membrane staining in more than $10-50 \%$ of cells and moderate complete membrane staining in more than $50 \%$ of cells; $4+$, strong complete membrane staining in more than $50 \%$ of cells. To compare aspartyl betahydroxylase protein expression and clinicopathological features of hepatocellular carcinoma, we regarded $3+$ and $4+$ cases as the high group and
$1+$ and $2+$ cases as the low group. Equivocal stains were considered negative. ${ }^{11,23}$

\section{Statistical Analysis}

All statistical calculations were carried out using of the SPSS.11 software. The differences between the aspartyl beta-hydroxylase mRNA overpression in hepatocellular carcinomas and nontumorous liver tissues were statistically analyzed using paired $t$-test or unpaired Student's $t$-test for single comparisons, and one-way analysis of variance (ANOVA) for multiple comparisons. The differences between the aspartyl beta-hydroxylase protein expression and clinicopathological features of hepatocellular carcinoma were statistically analyzed using $\chi^{2}$ test. Pearson's correlation was used to determine whether there is a positive or negative correlation between the RNA and protein expression. A difference was defined as significant at $P<0.05$ and a nonsignificant tendency was defined as $P<0.1$. A correlation coefficient $>0.5$ or $<-0.5$ was considered significant in Pearson's correlation.

\section{Results}

\section{RT-PCR Results of Expression of Aspartyl Beta-Hydroxylase in Hepatocellular Carcinoma}

Among 161 hepatocellular carcinomas, aspartyl beta-hydroxylase was overexpressed in 150 tumors (93\%). Aspartyl beta-hydroxylase was overexpressed in 45 of 48 unifocal small hepatocellular carcinomas (94\%). aspartyl beta-hydroxylase mRNA was either of a low level or not expressed in nontumorous liver (Figure 1). The relative aspartyl beta-hydroxylase and GAPDH gene expression levels in hepatocellular carcinoma and the corresponding nontumorous liver tissues found using real-time RT-PCR are shown in Figure 2. There are statistically significant differences between hepatocellular carcinoma and the corresponding nontumorous liver tissues $(P<0.001)$. The expression level was lowest in the normal liver tissues $(0.179 \pm 0.123, n=19)$. The value was $0.277 \pm 0.147$ for chronic hepatitis $(n=27), 0.426 \pm$ 0.142 for cirrhosis $(n=115)$, and $0.777 \pm 0.396$ for

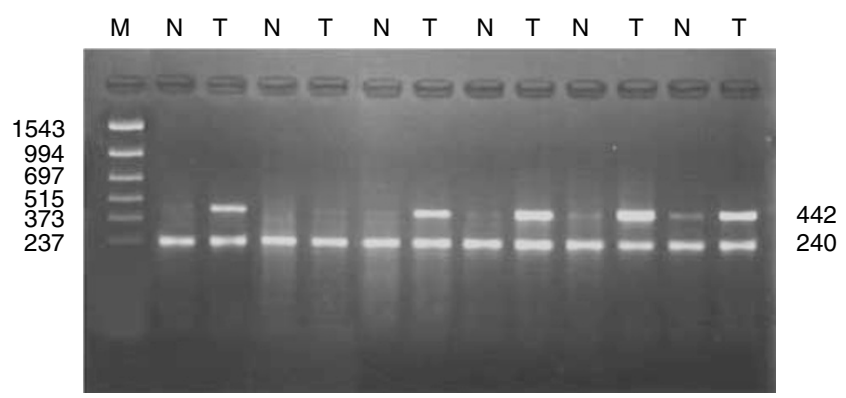

Figure 1 RT-PCR amplification of mRNA showed aspartyl betahydroxylase mRNA expression in paired hepatocellular carcinoma $(T)$ and nontumoros liver parenchyma $(N)$. 


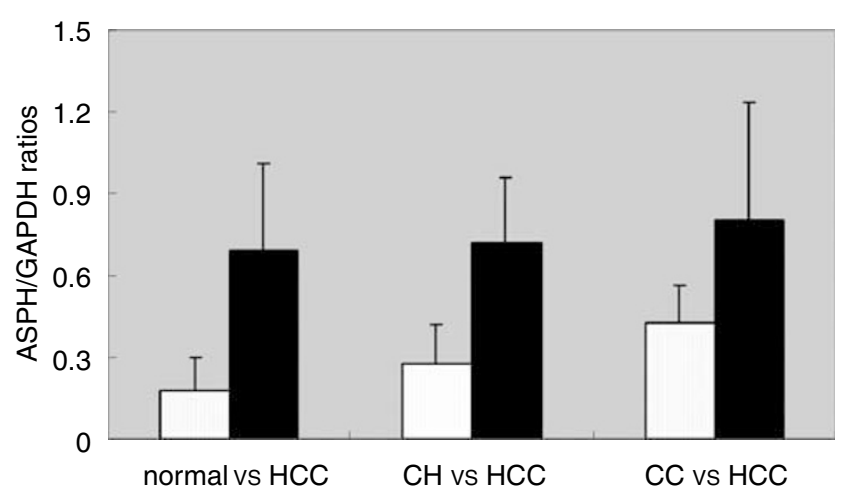

Figure 2 Real-time RT-PCR analysis for the expression of aspartyl beta-hydroxylase in hepatocellular carcinoma and adjacent nontumoros liver tissues. There are statistically significant differences between hepatocellular carcinoma and the corresponding nontumoros liver tissues $(P<0.001)$. Bars, mean; columns, SD. CH, chronic hepatitis; CC, cirrhosis.

hepatocellular carcinoma $(n=161)$. The unpaired $t$-test indicated significant differences between normal liver tissues, chronic hepatitis or cirrhosis, and hepatocellular carcinoma $(P<0.001)$. There was no significant difference between the normal liver tissues and chronic hepatitis or cirrhosis $(P=0.536)$. The value was $0.643 \pm 0.355$ for well differentiated $(n=53), 0.806 \pm 0.393$ for moderately differentiated $(n=80)$, and $0.946 \pm 0.407$ for poorly differentiated $(n=28)$. The unpaired $t$-test indicated significant differences between well differentiated and moderately differentiated $(P=0.017)$, and between well differentiated and poorly differentiated $(P=0.001)$. There was no significant difference between the moderately differentiated and poorly differentiated $(P=0.111)$. These observations strongly suggest that the degree of relative aspartyl beta-hydroxylase gene expressions positively correlated with the progress of histologic grade in hepatocellular carcinoma. The value was $0.641 \pm 0.287$ for not intrahepatic metastasis $(n=54)$ and $0.846 \pm 0.426$ for intrahepatic metastasis $(n=107)$. The unpaired $t$-test indicated significant differences between not intrahepatic metastasis and intrahepatic metastasis $(P=0.002)$. These observations strongly suggest that the degree of relative aspartyl beta-hydroxylase gene expressions positively correlated with the progression of histological grade and the presence of intrahepatic metastasis in hepatocellular carcinoma. However, there was no significant difference between aspartyl beta-hydroxylase expression levels and other clinicopathological findings such as age, HBV infection, serum AFP concentration, cirrhosis, tumor size, and tumor capsule in hepatocellular carcinoma.

\section{Immunohistochemistry Validation Studies}

We further validated the data by examining expression levels of aspartyl beta-hydroxylase at the protein level. Immunoreactivity was detected on the cell surface membranes, in the cytoplasm, and in perinuclear zones (Figure 3). Adjacent benign liver parenchyma was negative or weakly focal expressed. Of the 161 hepatocellular carcinomas, 150 (93\%) exhibited aspartyl beta-hydroxylase immunoreactivity using the monoclonal antibody to human aspartyl beta-hydroxylase. The results of correlation between tumor aspartyl beta-hydroxylase expression and tumor pathological features are shown in Table 1. A significantly higher tumor aspartyl betahydroxylase protein expression level was associated with the presence of intrahepatic metastasis $(P=0.036)$ and the progression of histological grade $(P=0.018$, well differentiated $v s$ moderately differentiated; $P=0.006$, well differentiated vs poorly differentiated). However, there was no significant difference between aspartyl beta-hydroxylase expression levels and other clinicopathological findings such as age, HBV infection, serum AFP concentration, cirrhosis, and tumor capsule in hepatocellular carcinoma.

The relative mRNA expression and protein expression of aspartyl beta-hydroxylase in the hepatocellular carcinoma was significantly correlated $(r=0.6594, P<0.0001)$ (Figure 4$)$, indicating that the expression is regulated at the transcription level, and mRNA level can represent the protein expression level.

\section{Discussion}

Aspartyl beta-hydroxylase is an alpha-ketoglutaratedependent dioxygenase that hydroxylates aspartate and asparagine residues in EGF-like domains of proteins. ${ }^{24} \mathrm{~A}$ series of reports have documented that deletion mutants, lacking the EGF-repeat-rich extracellular portions of Drosophila Notch or of homologous invertebrate and vertebrate proteins, which are involved in cell fate determinations and cellular differentiation, are gain-of-function mutants. This suggests that in these transmembrane proteins, the extracellular domain regulates signal transduction by the cytoplasmic domain..$^{12,24-26}$ In vivo and in vitro experiments have demonstrated that highlevel aspartyl beta-hydroxylase expression is linked to malignant transformation and invasive growth of malignant neoplasms. ${ }^{27,28}$ It has been demonstrated that overexpression of the aspartyl beta-hydroxylase cDNAs in NIH-3T3 cells induces a transformed phenotype manifested by increased numbers of transformed foci, anchorage-independent growth, and tumorigenesis in nude mice. In addition, intact aspartyl beta-hydroxylase enzyme was found to be required for aspartyl beta-hydroxylase-associated transformation. ${ }^{10}$ Our results are consistent with the hypothesis that overexpression of the aspartyl beta-hydroxylase gene is associated with hepatocellular carcinoma. The protein expression level of aspartyl beta-hydroxylase in the hepatocellular carcinoma was parallel with the mRNA expression 

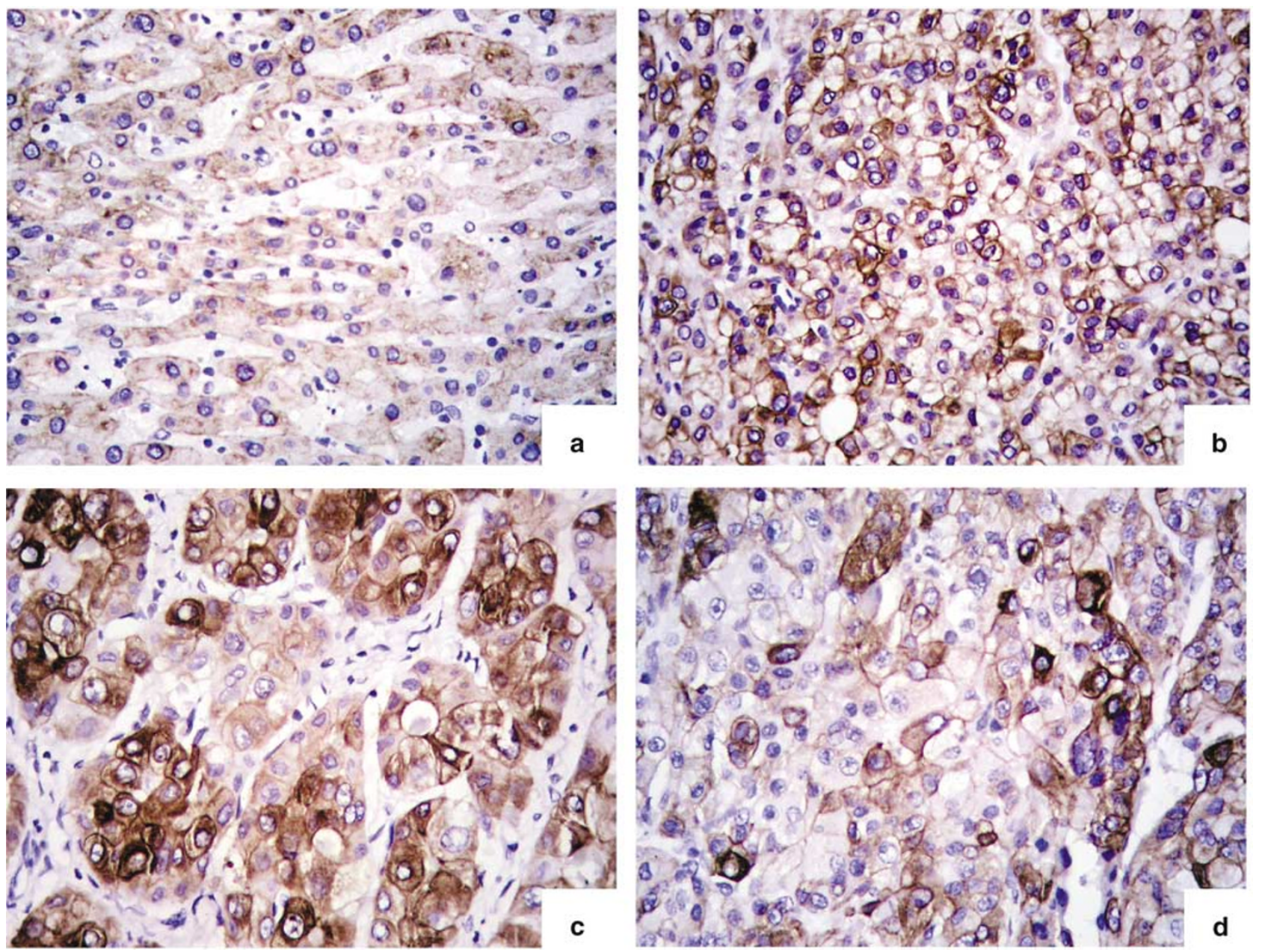

Figure 3 Aspartyl beta-hydroxylase immunoreactivity in hepatocellular carcinoma and nontumoros liver tissue. Nontumoros hepatic parenchyma was negative or weakly focal positive (a); High immunoreactivity was detected on the cell surface membranes (b), in the cytoplasm (c), and in membranes and perinuclear zones (d) in hepatocellular carcinoma.

level, indicating that the expression is regulated at the transcription level, and mRNA level can represent the protein expression level. Further investigation is required to determine whether the substantially increased activity of aspartyl betahydroxylase in carcinomas is merely associative or contributes to the development and/or maintenance of the malignant phenotype.

This study demonstrates that a high percentage of hepatocellular carcinomas exhibit increased immunoreactivity with the aspartyl beta-hydroxylase monoclonal antibody. Recent studies revealed that the aspartyl beta-hydroxylase is overexpressed in four of 10 hepatocellular carcinomas and a number of other malignant neoplasms, including those of gastrointestinal, mammary, bronchial, pancreatic, or biliary origin, but not in most normal adult tissues. ${ }^{10-12,28}$ A research showed that aspartyl betahydroxylase has an important role in regulating invasive or metastatic tumor cell growth of human cholangiocarcinoma, and that high levels of aspartyl beta-hydroxylase expression correlate with poor prognosis. ${ }^{11}$ Our results also showed that a significantly higher tumor aspartyl beta-hydroxylase protein expression level was associated with the presence of intrahepatic metastasis and the progression of histological grade. Among 48 unifocal small hepatocellular carcinomas, aspartyl beta-hydroxylase was overexpressed in 45 tumors (94\%). However, there was no significant difference between aspartyl beta-hydroxylase expression levels and other clinicopathological findings such as age, HBV infection, serum AFP concentration, cirrhosis, and tumor capsule in hepatocellular carcinoma. Therefore, although aspartyl beta-hydroxylase is not specific for hepatocellular carcinomas because their expression may also be increased with cholangiocarcinoma and metastatic adenocarcinoma, the results suggest that the aspartyl beta-hydroxylase could possibly be used as a prognostic marker for hepatocellular carcinoma because the corresponding epitopes are neither expressed in normal counterpart tissues nor upregulated with chronic hepatitis or cirrhosis. 
Table 1 Clinicopathologic factors and aspartyl beta-hydroxylase expression in hepatocellular carcinomas based on immunohistochemistry

\begin{tabular}{|c|c|c|c|c|c|}
\hline \multirow[t]{2}{*}{ Variables } & \multirow[t]{2}{*}{$\mathrm{n}$} & \multicolumn{3}{|c|}{ ASPH immunoreactivity } & \multirow[t]{2}{*}{$\mathrm{P}$} \\
\hline & & - & Low & High & \\
\hline \multicolumn{6}{|l|}{ Sex } \\
\hline $\mathrm{M}$ & 116 & 7 & 25 & 84 & NS \\
\hline $\mathrm{F}$ & 45 & 4 & 8 & 33 & \\
\hline \multicolumn{6}{|l|}{ Age } \\
\hline Less than median & 78 & 5 & 20 & 53 & NS \\
\hline Greater than median & 83 & 6 & 13 & 64 & \\
\hline \multicolumn{6}{|l|}{ Serum AFP level $(\mu \mathrm{g} / \mathrm{l})$} \\
\hline$<20$ & 55 & 4 & 12 & 39 & NS \\
\hline$\geq 20$ & 106 & 7 & 21 & 78 & \\
\hline \multicolumn{6}{|l|}{$H B s A g$} \\
\hline Positive & 122 & 8 & 22 & 91 & NS \\
\hline Negative & 39 & 3 & 10 & 26 & \\
\hline \multicolumn{6}{|l|}{ Tumor size } \\
\hline$\leq 2 \mathrm{~cm}$ & 48 & 4 & 8 & 36 & NS \\
\hline$>2 \mathrm{~cm}$ & 113 & 7 & 25 & 81 & \\
\hline \multicolumn{6}{|l|}{ Histological grade } \\
\hline Well differentiated & 53 & 5 & 18 & 30 & \\
\hline Moderately differentiated & 80 & 4 & 13 & 62 & 0.018 \\
\hline Poorly differentiated & 28 & 2 & 2 & 24 & 0.006 \\
\hline \multicolumn{6}{|l|}{ Liver cirrhosis } \\
\hline Absent & 66 & 4 & 14 & 48 & NS \\
\hline Present & 95 & 7 & 19 & 69 & \\
\hline \multicolumn{6}{|l|}{ Tumor capsule } \\
\hline Intact & 48 & 4 & 13 & 31 & NS \\
\hline Absent or not intact & 113 & 7 & 20 & 86 & \\
\hline \multicolumn{6}{|l|}{ Intrahepatic metastasis } \\
\hline Not observed & 54 & 5 & 16 & 33 & 0.036 \\
\hline Observed & 107 & 6 & 17 & 84 & \\
\hline Total & 161 & 11 & 33 & 117 & \\
\hline
\end{tabular}

$P=0.018$ (well differentiated $v s$ moderately differentiated); $P=0.006$ (well differentiated vs poorly differentiated); $P=0.036$ (not observed intrahepatic metastasis vs observed intrahepatic metastasis).

ASPH: aspartyl beta-hydroxylase.

Given their negative or weakly focal expression in hepatocytes as well as other normal tissues, this marker could also be used to immunotarget antitumor agents. Antisense and not sense or mutated antisense aspartyl beta-hydroxylase oligodeoxynucleotides significantly inhibited aspartyl beta-hydroxylase expression and motility in cholangiocarcinoma cells, human A549 lung carcinoma cells, and neuroblastoma Sy5y cells..$^{25,27,29,30}$ Monoclonal or polyclonal antisera against aspartyl beta-hydroxylase coupled to antitumor agents would allow specific targeting of therapies against cells expressing this surface antigen. ${ }^{25,30}$ Further investigation is required to determine whether the antisense aspartyl beta-hydroxylase oligodeoxynucleotides, monoclonal or polyclonal antisera

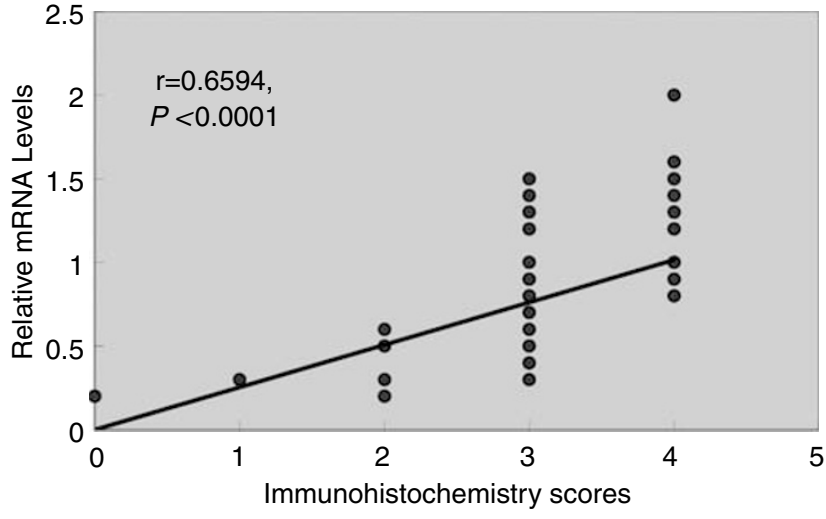

Figure 4 Relationship between relative gene expression and percentage of positive cell surface membranes of aspartyl betahydroxylase in hepatocellular carcinoma.

against aspartyl beta-hydroxylase can inhibit aspartyl beta-hydroxylase expression and motility in hepatocellular carcinoma.

In summary, aspartyl beta-hydroxylase gene is frequently overexpressed in hepatocellular carcinoma, including small hepatocellular carcinoma, indicating that overexpression of aspartyl betahydroxylase plays a role in the development and progression of hepatocellular carcinoma. Aspartyl beta-hydroxylase could possibly be used as a prognostic marker and an immunotarget for antitumor agents for hepatocellular carcinoma and other carcinomas. Further investigation is required to define the role of the aspartyl beta-hydroxylase in neoplasms to delineate the exact molecular pathways leading to hepatocarcinogenesis.

\section{Acknowledgement}

This study was supported by the National Natural Science Foundation of China, No. 30370645.

\section{References}

1 Wu MC, Shen F. Progress in research of liver surgery in China. World J Gastroenterol 2000;6:773-776.

2 Tang ZY. Treatment of hepatocellular carcinoma. Digestion 1998;59:556-562.

3 Bosch FX, Ribes J, Borras J. Epidemiology of primary liver cancer. Semin Liver Dis 1999;19:271-285.

4 Thorgeirsson SS, Grisham JW. Molecular pathogenesis of human hepatocellular carcinoma. Nat Genet 2002;31:339-346.

5 Feitelson MA, Sun B, Satiroglu Tufan NL, et al. Genetic mechanisms of hepatocarcinogenesis. Oncogene 2002;21:2593-2604.

6 Taouli B, Losada M, Holland A, et al. Magnetic resonance imaging of hepatocellular carcinoma. Gastroenterology 2004;127:S144-S152.

7 Baron RL, Brancatelli G. Computed tomographic imaging of hepatocellular carcinoma. Gastroenterology 2004;127:S133-S143. 
8 Suriawinata A, Xu R. An update on the molecular genetics of hepatocellular carcinoma. Semin Liver Dis 2004;24:77-88.

9 Feitelson MA, Pan J, Lian Z. Early molecular and genetic determinants of primary liver malignancy. Surg Clin North Am 2004;84:339-354.

10 Ince N, de la Monte SM, Wands JR. Overexpression of human aspartyl (asparaginyl) beta-hydroxylase is associated with malignant transformation. Cancer Res 2000;60:1261-1266.

11 Maeda T, Taguchi K, Aishima S, et al. Clinicopathological correlates of aspartyl (asparaginyl) beta-hydroxylase over-expression in cholangiocarcinoma. Cancer Detect Prev 2004;28:313-318.

12 Lavaissiere L, Jia S, Nishiyama M, et al. Overexpression of human aspartyl(asparaginyl)beta-hydroxylase in hepatocellular carcinoma and cholangiocarcinoma. J Clin Invest 1996;98:1313-1323.

13 Hirohashi S, Blum HE, Ishak KG, et al. Tumours of the liver and intrahepatic bile ducts. In: Hamilton SR, Aaltonen LA (eds). Pathology and Genetics. Tumours of the Digestive System. World Health Organisation Classification of Tumours. IARC Press: Lyon, 2000, pp 157-202.

14 Geiss GK, An MC, Bumgarner RE, et al. Global impact of influenza virus on cellular pathways is mediated by both replication-dependent and -independent events. J Virol 2001;75:4321-4331.

15 Mididoddi S, McGuirt JP, Sens MA, et al. Isoformspecific expression of metallothionein mRNA in the developing and adult human kidney. Toxicol Lett 1996;85:17-27.

16 Wong N, Chan KY, Macgregor PF, et al. Transcriptional profiling identifies gene expression changes associated with IFN-alpha tolerance in hepatitis C-related hepatocellular carcinoma cells. Clin Cancer Res 2005;11: 1319-1326.

17 Smith MW, Yue ZN, Geiss GK, et al. Identification of novel tumor markers in hepatitis $C$ virus-associated hepatocellular carcinoma. Cancer Res 2003;63:859-864.

18 Cheung ST, Wong SY, Leung KL, et al. Granulinepithelin precursor overexpression promotes growth and invasion of hepatocellular carcinoma. Clin Cancer Res 2004;10:7629-7636.

19 Pfaffl MW. A new mathematical model for relative quantification in real-time RT-PCR. Nucleic Acids Res 2001;29:e45.
20 Spivack SD, Hurteau GJ, Jain R, et al. Gene-environment interaction signatures by quantitative mRNA profiling in exfoliated buccal mucosal cells. Cancer Res 2004;64:6805-6813.

21 De Preter K, Speleman F, Combaret V, et al. Quantification of MYCN, DDX1, and NAG gene copy number in neuroblastoma using a real-time quantitative PCR assay. Mod Pathol 2002;15:159-166.

22 Miyazawa J, Mitoro A, Kawashiri S, et al. Expression of mesenchyme-specific gene HMGA2 in squamous cell carcinomas of the oral cavity. Cancer Res 2004; 64:2024-2029.

23 Lal P, Salazar PA, Hudis CA, et al. HER-2 testing in breast cancer using immunohistochemical analysis and fluorescence in situ hybridization: a singleinstitution experience of 2279 cases and comparison of dual-color and single-color scoring. Am J Clin Pathol 2004;121:631-636.

24 Dinchuk JE, Henderson NL, Burn TC, et al. Aspartyl beta-hydroxylase (Asph) and an evolutionarily conserved isoform of Asph missing the catalytic domain share exons with junctin. J Biol Chem 2000;275:3954339554.

25 Maeda T, Sepe P, Lahousse S, et al. Antisense oligodeoxynucleotides directed against aspartyl (asparaginyl) beta-hydroxylase suppress migration of cholangiocarcinoma cells. J Hepatol 2003;38: 615-622.

26 Dinchuk JE, Focht RJ, Kelley JA, et al. Absence of posttranslational aspartyl beta-hydroxylation of epidermal growth factor domains in mice leads to developmental defects and an increased incidence of intestinal neoplasia. J Biol Chem 2002;277:12970-12977.

27 Sepe PS, Lahousse SA, Gemelli B, et al. Role of the aspartyl-asparaginyl-beta-hydroxylase gene in neuroblastoma cell motility. Lab Invest 2002;82:881-891.

28 Palumbo KS, Wands JR, Safran H, et al. Human aspartyl (asparaginyl) beta-hydroxylase monoclonal antibodies: potential biomarkers for pancreatic carcinoma. Pancreas 2002;25:39-44.

29 Ho SP, Scully MS, Krauthauser CM, et al. Antisense oligonucleotides selectively regulate aspartyl betahydroxylase and its truncated protein isoform in vitro but distribute poorly into A549 tumors in vivo. J Pharmacol Exp Ther 2002;302:795-803.

30 Gores GJ. Cholangiocarcinoma: preventing invasion as anti-cancer strategy. J Hepatol 2003;38:671-673. 